Vol. 7, No. 1, 2017

\title{
MEANS OF LIGHTNING PROTECTION OF OVERHEAD POWER TRANSMISSION LINES WITH ISOLATED NEUTRAL
}

\author{
Taras Binkevych \\ Lviv Polytechnic National University, Lviv, Ukraine \\ Taras.V.Binkevych@lpnu.ua
}

(C) Binkevych T., 2017

\begin{abstract}
Main models and means of lightning protection of overhead power transmission lines with covered wires in grids with voltage from 6 to $35 \mathrm{kV}$ are considered in the article. The specific features of covered wires in comparison with bare wires are given. The principle of operation and main structural parts of the means of lightning protection are described, possible variants of installing the means of lightning protection are shown. The analysis of the effectiveness of existing means, as well as the main protecting means requirements according to normative documents has been carried out.
\end{abstract}

Key words: lightning protection of overhead power transmission lines, coated wires, long flash-over arresters, multi-chamber arresters, non-linear surge arresters.

\section{Introduction}

The power supply reliability is determined by the accident-free operation of all elements of the power grid. There are numerous kinds of possible equipment damages, which cannot be detected by diagnostic troubleshooting, since their cause is difficult to be found out. Sometimes lightning cannot be detected as the main cause of the breakdown. So, it is important to carry out the thorough analysis of the conditions of appearance and development of the breakdown straight after its occurrence.

Lightning influences (direct lightning strokes and induced atmospheric surges) are the constituent part of the general statistics of electrical equipment breakdowns belonging to the category of natural phenomena. Nevertheless, the question what quantitative part of all damages is made by lightning outages is rather difficult to solve, since they are not recorded separately in most power systems. Regardless of the classification (cause of breakdown, cause of damage development, occurrence of a failure), the quantitative part of breakdowns caused by natural phenomena is rather large: in different years it fluctuates from 8 to $50 \%$, or, on average, from 16 to $20 \%$ of all annual system breakdowns [1].
Lightning can damage insulators, power transmission towers and wires; it can cause line-to-ground faults, arc surge voltage and automatic line disconnections. Due to the low level of impulse strength of line insulation, overhead lines (OL) with voltage of $6-35 \mathrm{kV}$ undergo lightning disconnections, because almost all lightning surges cause the transition of power-line frequency voltage into the power arc.

Besides, the introduction of distributive OLs with covered line wires (COLs), which have some operational and technical advantages in comparison with OLs with bare wires (they are less damageable, more reliable, safer and with smaller dimensions), conditions the use of certain lightning protection systems for preventing insulation breakdowns and burning out wires by power currents of short circuit fault [6].

The peculiarity of the lightning protection of COLs is that without taking some special measures when lightning arc-over occurs on line insulators accompanied by the breakdown of the hard wire insulation, the arc with voltage of power-line frequency occurs. This arc is not able to move along the wire and burns in the place of insulation breakdown until the line disconnection. This can cause burning of wire insulation and line insulators, and, in the case of heavy currents of short circuit burning down the wire (Fig. 1).

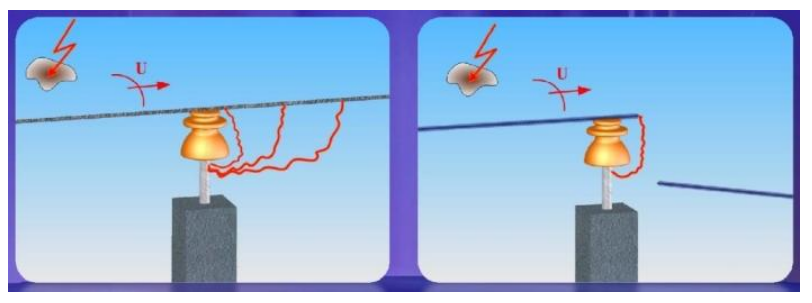

Fig. 1. Peculiarities of arc moving along bare $O L$ wire and $\mathrm{COL}$ wire.

Considering the problem of lightning protection of COL, it is necessary to analyze existing models, such as American, Finnish and Japanese systems [12]. 
In American lightning protection system, the insulation of the part of the wire near to the insulator is eliminated and arc-resistant clips are mounted. When over-arc occurs, it moves along the section bounded by clips, where burns until the line is disconnected (Fig. 2). The disadvantage of the American protecting system is the necessity of disconnecting the lines, as well as the limited service life of arc-resistant clips.

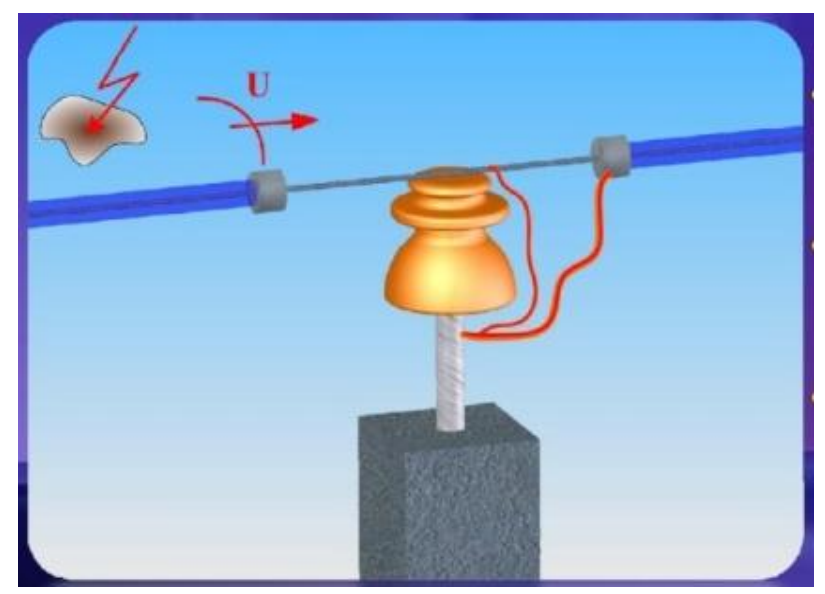

Fig. 2. Flow chart of arc-resistant clips.

In the Finnish system of lightning protection, arcing horns together with a spiral fixture are mounted on all three wires near the insulators. They are to provide the withdrawal of flashovers from each wire and the transition of possible one-phase arcs at least into twophased arcs. Therefore, the wires should be protected from burning out, because the horns encourage the flashover to occur between themselves rather than across the surface of the insulator they protect (Wiki). Besides, arc is extinguished after the line disconnection (Fig. 3).

Protecting wires from burning out, this construction does not protect the insulation from lightning surges and does not eliminate the occurrence of short circuits and line disconnections after the lightning impacts. Moreover, the particular arrangement of the horns is intended for transforming one-phase short circuits into many-phase ones only for causing the line disconnection.

Such principle of operation does not agreed with the main idea of functioning electric grids with isolated neutral, for which one-phase short circuit does not mean emergency state requiring line disconnection. In this case one problem, namely, that of burning out wires, is solved at the expense of adding other problems. The disadvantages of this system are: burning out wires while arc is burning on the spiral, electro-dynamic blow to the equipment, damaging plants near the power towers, line disconnections and horn burning, the last requiring their further replacement.

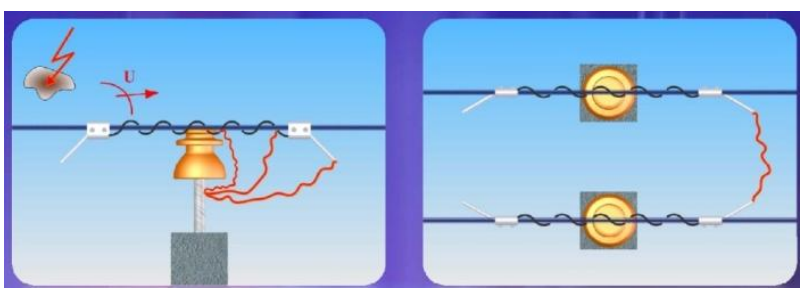

Fig. 3. Flow chart of arcing horns.

The Japanese system of lightning protection contains non-linear surge arresters (NSA) intended for lightning current of $2.5 \mathrm{kA}$ and mounted in parallel with each COL insulator connecting them to the wire through a spark gap. This effectively prevents arc short circuits as well as line disconnections during induced surges (Fig. 4). Main disadvantages of this system are high cost of equipment and the fact that under the conditions of direct lightning strokes the arresters are damaged and have to be replaced.

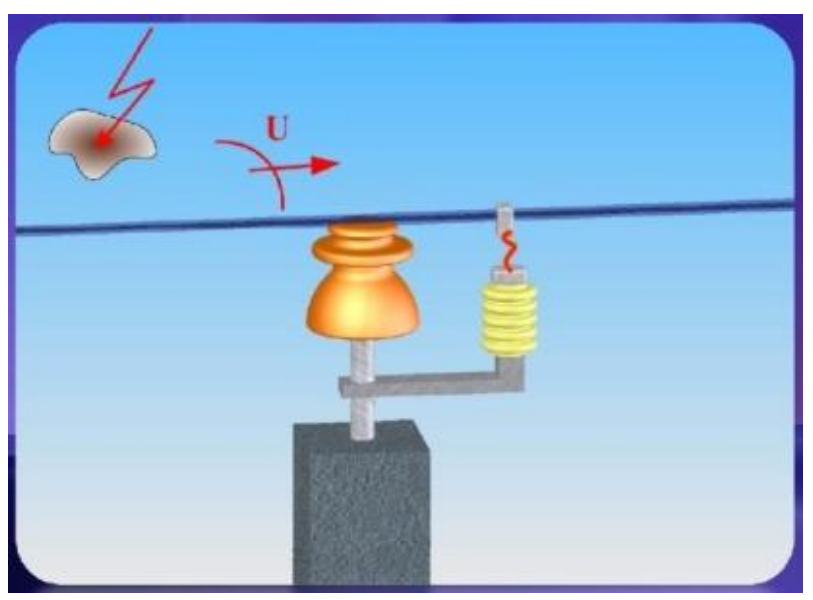

Fig. 4. Flow chart of COL with non-linear surge arresters.

The mounting characteristics of non-linear surge arresters are regulated by [5] with meeting the requirements of Chapter 4.2 of [9]. According to [5], on the towers with NSA from 6 to $35 \mathrm{kV}$ with pin insulators and base-pin insulators following protecting devices are used for the protection of wires against their burning out in the cases of lightning arc-overs of insulation:

- $\quad$ long flash-over arresters (LFA);

- multi-chamber insulator arresters (MCA);

- non-linear surge arresters (NSA) with a spark gap (SG).

\section{Long flash-over arresters}

Long flash-over arresters are lightning protection devices which, according to their design parameters, technical characteristics and functional abilities, make up a special class of protection equipment $[2,3]$. 
The operation principle of all LFA consists in limiting the lightning surges on $\mathrm{COL}$ at the expense of sparkover along the insulator surface of the arrester with the length of discharge channel being several times longer, than the height of the insulation protected. Follow currents of industrial frequency are reduced due to decreasing the mean value of operating voltage gradient along the lightning flashover channel.

The main peculiarity of LFA class is that they cannot be destroyed or damaged by lightning and arc currents, because they flow beyond the devices along the LFA surface. This characteristic, unique for lightning protection equipment, is accompanied with constructive simplicity.

The length of LFA discharge gap is several times longer, than the height of the insulation and has lower pulse electrical strength, than the strength of insulation. It can be explained by the peculiarities of creeping discharge effect, which develops on the surface of the insulating gap. The voltage of the creeping charge weakly depends on the distance between the electrodes, so long gaps can be covered by comparatively low voltages. This effect is used as the basis of the construction of long flash-over arresters.

LFA loop arrester (LFA-L) (Fig. 5, $a$ ) is a metal rod covered with a layer of polyethylene insulation and bent like a loop, installed on the earthed electrode of the tower. The loop is passed through a metal tube, which is placed in the middle of the loop, and spark gap is established between the tube and the rod. Due to great capacitance between the metal tube and the rod, all voltage is applied between the wire and the tube.

During the spark gap breakdown, surge voltage is applied between the tube and the metal rod and, as a result, the creeping charge occurs from the tube and develops along the insulation surface moving towards its connection to the earth through a fixing unit [11].

The variety of such an arrester is a modular LFA (LFA-M), which consists of two pieces of cable with an insulating cord made of semi-conductor material. Pieces of cable are connected to form three flashover modules (Fig. 5, b). The segments of semi-conductor core are connected with metal electrodes through the inner spark gaps. When lightning impulse occurs, they overlap and the semi-conductor core of upper piece of cable, whose resistance is $R$, applies the high potential $U$ to the surface of the lower piece in its middle part.

Similarly, the semi-conductive core of the lower piece of the cable applies the low potential 0 to the surface in the midle of the upper piece of the cable. Therefore, the total voltage $U$ is applied to each flashover module at the same moment, so that on all three modules creeping discharges can simultaneously occur developing into a single long flashover channel [13].

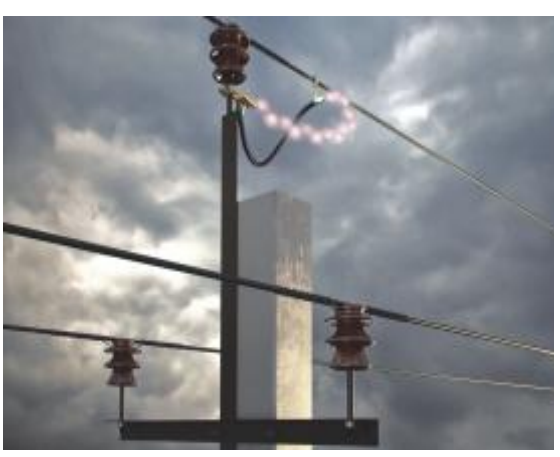

$a$

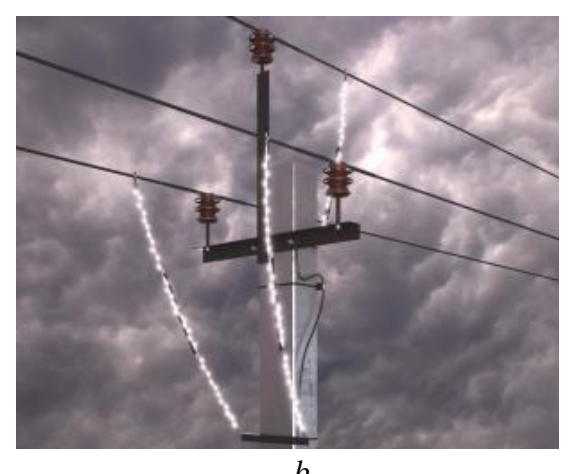

$b$

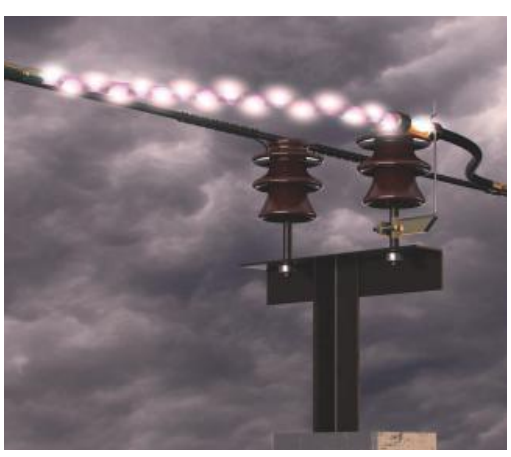

$c$

Fig. 5. Pictures of testing: LFA-L (a), LFA-M(b), LFA-S (c).

The main element of stub LFA (LFA-S) is a piece of special cable with single aluminium core and three-level insulation made of cross-linked polyethylene. The one third part of the cable piece contains intermediary ring electrodes providing the division of the flashover channel into several sections (Fig. 5, c). When surge voltage occurs on the OL wire, metal tube on the arrester cable acquires the same high potential, as the wire. Therefore, all lightning surge voltage proves to be applied to the spark gap between the tube and the earthed rod electrode.

When voltage reaches $50-70 \mathrm{kV}$, the breakdown of the gap takes place, and metal tube on the surface of the cable gets zero potential. So, surge voltage is applied between the cable core and metal tube on its surface. Under the influence of this surge voltage, the creeping discharge develops along the insulation surface of the arrester. The OL wire proves to be connected with the earthed rod via a long discharge channel divided into 
separate sections by the ring electrodes. During the first transition of the pulse current through zero, the discharge dies out without creating the power arc and so prevents the occurrence of short circuit and OL from line disconnection.

According to [5], the LFA-M are used for the protection of COLs with voltage of $6-10 \mathrm{kV}$ and wires located at a distance of $0.5 \mathrm{~m}$ from one another. The LFA-S are used for the protection of COLs with the same voltage at the places of double fastening of wires instead of LFA-L.

\section{Multi-chamber insulator arresters}

As the result of improving lightning protection systems, the arresters for OLs with voltage of 6-35 kV or even higher were developed which are called multichamber arresters (MCA). A new arrester has also been proposed uniting the properties of insulator and arrester (MCIA).

Basically, the MCIA consists of common insulators (glass, porcelain or polymer), on which MCA is mounted. Due to this constructive peculiarity, the insulator does not lose its properties, but, in addition, acquires the properties of the arrester. Therefore, when MCIA is used on the OL, it is not necessary to use lightning protection static wires. It causes the decrease in the height, mass and costs of power towers, as well as in cost of the OL as a whole. It also provides the reliable lightning protection of OLs and decreases losses caused by undersupply of energy and operating costs [11].

The main element of the multi-chamber arrester (MCA) as well as MCIA is a multi-chamber system (Fig. 6) consisting of numerous spherical electrodes inside silicone rubber. Holes directed out of the rubber shape are made between the electrodes. They act as miniature gas discharge chambers. When a lightning overvoltage impulse is applied to the arrester, it breaks down gaps between electrodes.

Due to the fact, that the discharges between intermediate electrodes take place inside chambers of a very small volume, a pair of metal electrodes acts like a tiny discharge chamber, so each arc is blown out into the ambient air under the high pressure occurred in the channel. It means, that the resulting high pressure drives spark discharge channels between electrodes to the surface of the insulating body and hence outside, into the air around the arrester. A blow-out action and an elongation of inter-electrode channels lead to the increase in total resistance of all channels, i. e. that of the arrester, which limits the current of lightning surge.

After finishing the lightning surge, the arresters undergo the voltage of industrial frequence. As performed tests have shown, in arresters with MCS two kinds of extinguishing spark discharges are possible:

- when follow current of $50 \mathrm{~Hz}$ crosses zero;

when the instantaneous value of lightning surge impulse drops to a level equal to or larger than the instantaneous value of industrial frequency voltage, i. e. lightning surge current gets extinguished without follow current of the grid.
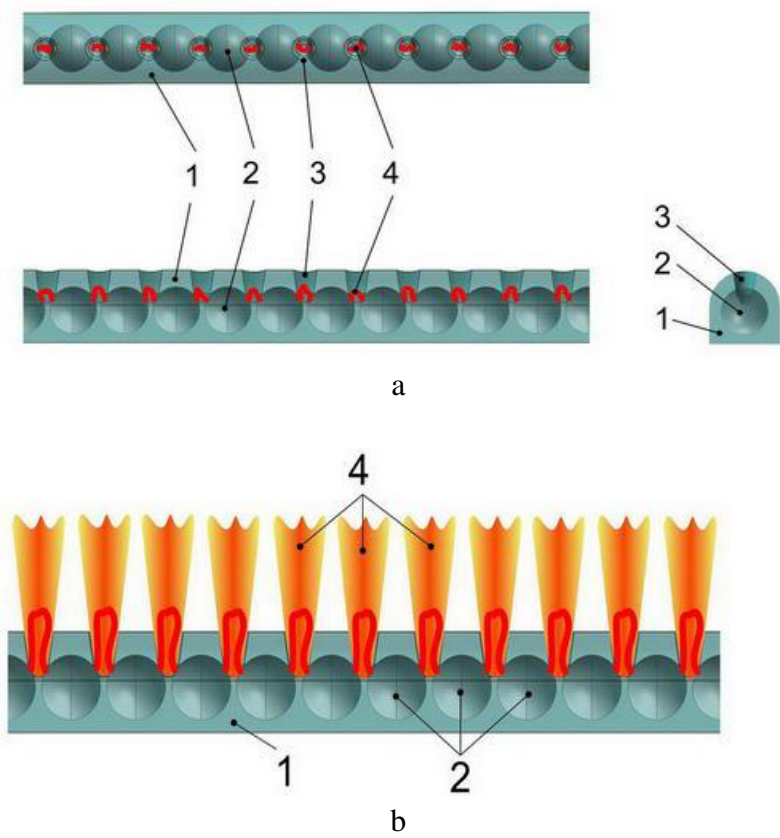

Fig. 6. Multi-chamber system (MCS): diagram showing the discharge onset instant (a); diagram showing the discharge end instant (b); 1 - silicon rubber shape;

2 - intermediate electrodes; 3 - arc quenching chambers, 4 -discharge channel.

According to [5], the choice of the type of protecting device (PD) is performed at the design stage of the COL with voltage of $6-35 \mathrm{kV}$ agreeing it with the customer for the line and taking into account their technical parameters. PD are to be mounted:

- one device on each tower (for each wire) with the interchange of phases;

- on two-wire COLs with voltage from 6 to $10 \mathrm{kV}$ PD should be mounted on both circuits in such a way as to protect only one pair of similar phases on each

- tower, with the same interchange principle as for one-wire COLs. 


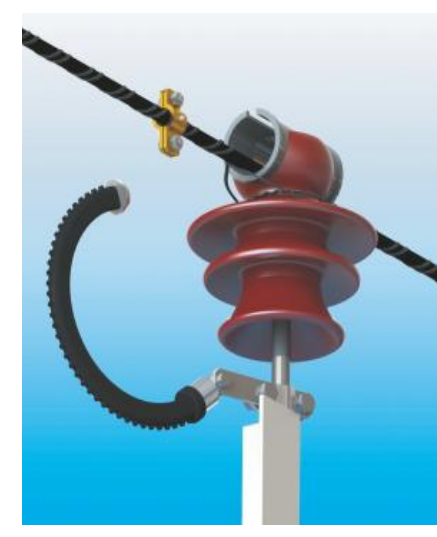

$a$

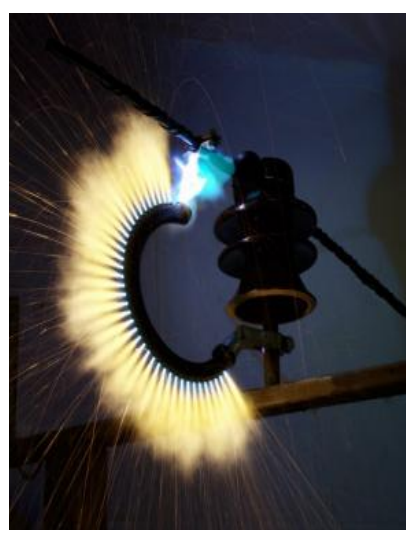

$b$

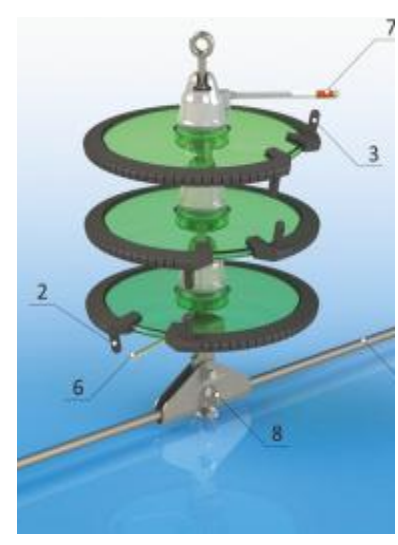

$c$

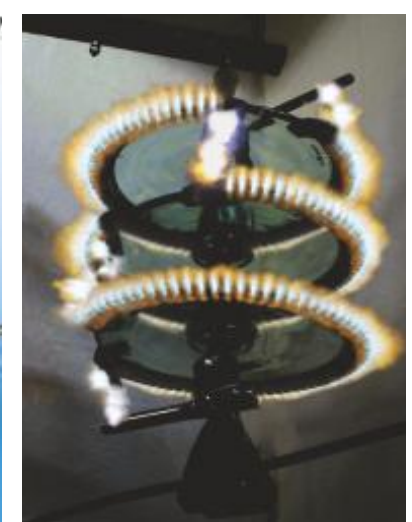

$d$

Fig. 7. Mounting of PMK-20-IV-УXЛIon the line (a); picture of testing PMK-20-IV-УXЛI (b); general arrangement of $Г I P M K-35-3(c)$; picture of testing $\Gamma I P M K-35-3(d)$.

\section{Conclusions}

In the article the design philosophy of the coated wires are considered and the problem of their lightning protection is defined. The main means of lightning protection of overhead power transmission lines with coated wires are exemplified, the main operational principles and construction details are described, the possible variants of mounting the means of lightning protection are shown. The analysis of the effectiveness of existing means, as well as the main requirements to the means of lightning protection according to the normative documents is conducted.

The problem of lightning protection for coated wires has not been completely solved, because of some disadvantages the existing means possess. For example, the multi-chamber system allows uniting of some separate charges occurring between neighboring electrodes into integrated channel, which harms electrical equipment of the power transmission line, in which the insulator is used, as well as shortens operating time of the insulator itself.

\section{References}

[1] V. Cooray, ed. Lightning Protection. London, United Kingdom: The Institution of Engineering and Technology, 2010.

[2] I. Lishchak and T. Binkevich, "Modern lightning protection of overhead power transmission lines by $6,10 \mathrm{kV}$ by long flash-over arresters (ALF). Visnyk NU "Lvivska politekhnika”, no. 736, pp. 75-80. Lviv, Ukraine: Lviv Polytechnic National University, 2012. (Ukrainian).

[3] G. Podporkin, Development of long flash-over and multi-chamber arresters andisulator-arresters for lightning protection of overhead distribution and transmission lines", Plasma Physics and Technology, vol. 2, no. 3, pp. 241-250, 2015.

[4] Ye. Kalakutskiy, "Lightning protection of OL 6-220 kV by multi-chamber arresters and insulator-dischargers", in Proc. IVth Russian Conf. Transmission Lines 2010 - Design, Development and Experience of Operation, pp. 153-158. Novosybirsk, Russia, 2010. (Russian).

[5] Design requirements for overhead power transmission lines with coated wires of 6-35 kV. Kyiv, Ukraine: Ministry of Energy and Coal Industry of Ukraine, 2013. (Ukrainian).

[6] Practical policies on protection of distribution electrical grids with voltage of 0,4-10 kV from lightning overvoltage. Moscow, Russia: OAO "ROSEP", 2004. (Russian).

[7] N. Tikhodeyev, ed. Manual on protection of electrical grids 6-1150 kV from lightning and inner overvoltage. $2^{\text {nd }}$ ed. Saint Petersburg, Russia: Petersburg Institute of Energy for Professional Development of Ministry of Energy of Russian Federation, 1999. (Russian).

[8] Instruction on application, installation and operation of the means of overvoltage protection in electrical equipment with voltage of 6-750 kV. Kyiv, Ukraine: Ministry of Energy and Coal Industry of Ukraine, 2013. (Ukrainian).

[9] Operational regulations on installation of electrical equipment. $3^{\text {rd }}$ ed. Kyiv, Ukraine: Ministry of Fuel and Energy of Ukraine, 2010. (Ukrainian).

[10] Regulations of Ministry of Fuel and Energy of Ukraine on operation of consumers' electrical equipment. Kharkiv, Ukraine: Fort, 2012. (Ukrainian). 
[11] "Lightning protection of overhead lines", https://www.streamer.ru/streamer_products/ lightning-protection (Russian).

[12] "Lightning protection of overhead lines 6-35 kV by longflash-over arresters", http://www. slideshare. net/ anti4ek/635-9468650. (Russian).

[13] 'Lightning protection using FLS-M", http://sadiqmsk. blogspot.com/2010/04/lighting-protection-using-lfam.html

\section{ЗАСОБИ ГРОЗОЗАХИСТУ ПОВІТРЯ- НИХ ЛІНІЙ ЕЛЕКТРОПЕРЕСИЛАННЯ 3 ПРОВОДАМИ ІЗ ЗАХИСНИМ ПОКРИТТЯМ В МЕРЕЖАХ 3 ІЗОЛЬОВАНОЮ НЕЙТРАЛЛЮ}

\author{
Тарас Бінкевич
}

Розглянуто основні моделі та засоби грозозахисту повітряних ліній електропересилання 3 проводами із захисним покриттям у мережах, напруга яких становить 6-35 кВ. Наведено особливості проводів із захисним покриттям порівняно 3 неізольованими проводами. Описано принцип роботи, основні конструктивні елементи та відображено можливі варіанти встановлення засобів грозозахисту. Проведено аналіз ефективності наявних засобів, а також основні вимоги до засобів захисту відповідно до нормативних документів.

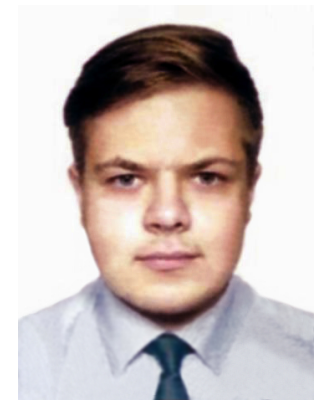

Taras Binkevych - graduated from the Institute of Electric Power Engineering and Control Systems of Lviv Polytechnic National University, Ukraine, and Lviv Commercial Academy, Ukraine (major Science of law). He is a postgraduate student at the Department of Electric Systems of Lviv Polytechnic National University, Ukraine. Scientific interests: lightning protection of the objects of power systems. 